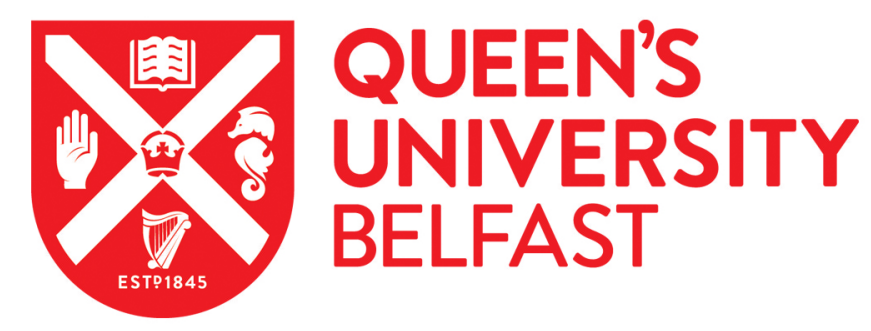

\title{
Does economic policy uncertainty predict the Bitcoin returns? An empirical investigation
}

Demir, E., Gozgor, G., Lau, M. C. K., \& Vigne, S. (2018). Does economic policy uncertainty predict the Bitcoin returns? An empirical investigation. Finance Research Letters. https://doi.org/10.1016/j.frl.2018.01.005

\author{
Published in: \\ Finance Research Letters
}

\section{Document Version:}

Peer reviewed version

\section{Queen's University Belfast - Research Portal:}

Link to publication record in Queen's University Belfast Research Portal

\section{Publisher rights}

Copyright 2017 Elsevier

This manuscript is distributed under a Creative Commons Attribution-NonCommercial-NoDerivs License

(https://creativecommons.org/licenses/by-nc-nd/4.0/), which permits distribution and reproduction for non-commercial purposes, provided the author and source are cited.

\section{General rights}

Copyright for the publications made accessible via the Queen's University Belfast Research Portal is retained by the author(s) and / or other copyright owners and it is a condition of accessing these publications that users recognise and abide by the legal requirements associated with these rights.

Take down policy

The Research Portal is Queen's institutional repository that provides access to Queen's research output. Every effort has been made to ensure that content in the Research Portal does not infringe any person's rights, or applicable UK laws. If you discover content in the Research Portal that you believe breaches copyright or violates any law, please contact openaccess@qub.ac.uk. 


\title{
Does Economic Policy Uncertainty Predict the Bitcoin Returns? An Empirical Investigation
}

\author{
Ender Demir, PhD \\ Istanbul Medeniyet University, Turkey \\ E-mail: ender.demir@medeniyet.edu.tr \\ Giray Gozgor, $\mathrm{PhD}$ (Corresponding Author) \\ Istanbul Medeniyet University, Turkey \\ E-mail: giray.gozgor@medeniyet.edu.tr \\ Chi Keung Marco Lau, PhD \\ University of Huddersfield, Huddersfield, United Kingdom \\ E-mail: c.lau@hud.ac.uk \\ Samuel A. Vigne \\ Queen's Management School, Queen's University Belfast, BT9 5EE, Northern Ireland, United \\ Kingdom \\ E-mail: s.vigne@,qub.ac.uk
}

\begin{abstract}
This paper analyzes the prediction power of the economic policy uncertainty (EPU) index on the daily Bitcoin returns. Using the Bayesian Graphical Structural Vector Autoregressive model as well as the Ordinary Least Squares and the Quantile-on-Quantile Regression estimations, the paper finds that the EPU has a predictive power on Bitcoin returns. Fundamentally, Bitcoin returns are negatively associated with the EPU. However, the effect is positive and significant at both lower and higher quantiles of Bitcoin returns and the EPU. In the light of these findings, the paper concludes that Bitcoin can serve as a hedging tool against uncertainty.
\end{abstract}

Key Words: bitcoin; cryptocurrencies; economic policy uncertainty; Bayesian graphical model; Structural vector autoregressive; Quantile-on-quantile regression

JEL Classification Codes: D81; G15; C22

$\underline{\text { Highlights }}$

We examine the prediction power of the EPU on the Bitcoin returns

The EPU has a predictive power on the Bitcoin returns

The negative response of the Bitcoin returns to the positive change in the EPU

The effect is positive and significant at both lower and higher quantiles

Bitcoin has a hedging capability against the uncertainty 


\section{Introduction}

Nakamoto (2008) introduced the Bitcoin, which is a digital currency and open-source online payment system. Bitcoin is fully decentralized without any central authority and control while depending on a sophisticated protocol. The supply of Bitcoin is limited to 21 million by the design of the protocol. Since its introduction, the market value of Bitcoin has grown rapidly. According to the data from http://www.coindesk.com, the market capitalization of Bitcoin has dramatically reached \$278 Billion from \$111 Billion for the period from November 15, 2017 to December 15, 2017. In addition to legal and technical debates, especially due to these record high performances, Bitcoin has hit the headlines recently.

Similarly, there is the rising interest in the literature by focusing on economic and financial determinants of the Bitcoin price. For instance, Dyhrberg (2016) shows that Bitcoin can be used as a hedging instrument against the stock market and the United States (U.S.) Dollar and it is a useful tool for both portfolio diversification and risk management.

Another strand of literature focuses on the efficiency of Bitcoin. Urquhart (2016) provides the supporting evidence on the inefficiency of Bitcoin market, but it is in the process of moving towards efficiency for the period from August 1, 2013, to July 31, 2016. Using the Bitcoin returns, Nadarajah and Chu (2017) show that the efficient market hypothesis is not valid. According to Bariviera (2017), the daily returns exhibit persistent (inefficiency) behavior until 2014, whereas the market is more informational efficient since 2014. Finally, the previous studies investigate the volatility of Bitcoin returns (Katsiampa, 2017), the price clustering (Urquhart, 2017), and the speculative bubbles (Cheah and Fry, 2015).

To the best of our knowledge, Bouri et al. (2017) is the only study to examine the relationship between uncertainty and Bitcoin market. The authors explore whether Bitcoin can serve as a hedge against uncertainty that is measured by the first principal component of 
the Volatility Indexes (VIXs) of 14 developed and developing stock markets. According to their results, Bitcoin acts as a hedge against uncertainty.

In a similar vein, our paper examines the prediction power of the daily economic policy uncertainty (EPU) index on the daily Bitcoin returns. Indeed, uncertainties about the decisions of governments and regularity bodies lead to decreases in the trust of investors to mainstream currencies and or to the entire economy especially after the global financial crisis of 2008-9. This is also the time when the Bitcoin was created. Therefore, by its nature, Bitcoin questions the effectiveness of standard economic and financial structures and the digital currencies are decentralized secure alternatives to the fiat currencies, especially during the times of economic and geopolitical unrest. Therefore, the changes in the EPU index can possibly affect Bitcoin returns. We find that Bitcoin can serve as a hedging tool against uncertainty at both lower and higher quantiles. In other words, an increase in EPU will help Bitcoin to meet what it promises and increase the attractiveness of Bitcoin.

The remainder of the paper is as follows. Section 2 describes our data, model, and methodology. Section 3 reports the results and discusses the findings. Section 4 concludes.

\section{Data, Model, and Methodology}

\subsection{Data and Empirical Model}

The paper considers the logarithmic returns of Bitcoin as the dependent variable for the period from July 18,2010 , to November 15,2017 . The number of observations is 2,678 . The starting date of the empirical analysis is due to the availability of the data and the daily frequency data are used. Following Katsiampa (2017), we obtain the data of the Bitcoin prices from http://www.coindesk.com/price/. We also use the daily EPU index in the U.S., 
which is developed by Baker et al. (2016). ${ }^{1}$ Using the EPU in the U.S. is not only related to the daily data availability, but also Bitcoin prices are mainly quoted in the USD. The correlation between the logarithmic returns of Bitcoin and the EPU index is -0.014 . At this stage, our paper estimates the following empirical model:

$$
\Delta \ln (B C P)_{t}=\alpha_{0}+\alpha_{1} \Delta \ln (E P U)_{t}+\varepsilon_{t}
$$

Where $\Delta \ln (B C P)_{t}$ and $\Delta \ln (E P U)_{t}$ represent the daily logarithmic returns of Bitcoin prices and the EPU index values, respectively. $\varepsilon_{t}$ is the error term.

\subsection{Econometric Methodology}

The Bayesian Graphical Structural Vector Autoregressive (BGSVAR) model can provide the contemporaneous and the delayed causality between the Bitcoin returns (i.e. the response variable) and the EPU index (i.e. the predictor variable). An SVAR model can define the dependence/causality, as such:

$$
Y_{t}=B_{0} Y_{t}+\sum_{i=1}^{p} B_{i} Y_{t-i}+\sum_{i=1}^{p} C_{i} Z_{t-i}+\varepsilon_{t}
$$

where $t=1, \ldots, T$ and $p$ is the maximum lag order. $Y_{t}$ and $Z_{t}$ are the vector of the returns of Bitcoin and the EPU index, respectively. We can write the reduced form of Eq. (2), as such:

$$
Y_{t}=A_{1} X_{t-1}+\ldots A_{p} X_{t-p}+u_{t}
$$

where $X_{t}=\left(Y_{t}, Z_{t}\right)^{\prime}=\left(X_{1 t}, X_{2 t}, \ldots, X_{n t}\right)^{\prime}$ is an $n=n_{y}+n_{z}$ dimensional time series; $B_{i}^{*}=\left(B_{i}, C_{i}\right), \quad 1 \leq i \leq p$, are $\left(n_{y} \times n\right)$ matrices of the unknown coefficients; $A_{0}=\left(I_{n_{y}}-B_{0}\right)$ is a $\left(n_{y} \times n_{y}\right)$ matrix; $A_{i}=A_{0}^{-1} B_{i}^{*}, 1 \leq i \leq p$, are $\left(n_{y} \times n\right)$ the reduced-form lag coefficient matrices; and $u_{t}=A_{0}^{-1} \varepsilon_{t}$ is an $\left(n_{y} \times 1\right)$ independently and identically

\footnotetext{
1 For the details of the EPU indexes, visit the website that is designed by Baker et al. (2016) (http://www.policyuncertainty.com).
} 
distributed reduced-form vector residual term with the zero mean and the covariance matrix $\Sigma_{u}$

In this paper, we apply the BGSVAR model of Ahelegbey et al. (2016) in order to handle the problems of the misidentification of the system of equations and implausible restrictions assumption (Bouri et al., 2018). The BGSVAR model maintains two simple representations, namely the Contemporaneous Network $(\mathrm{CN})$ and the Lagged Network (LN) causality structures. ${ }^{2}$ In addition, Bouri et al. (2018) use the Bayesian Graphical model to predict the BRICS stock market returns using the VIX index as a predictor along with other financial and macroeconomic variables. Following the spirit of Bouri et al. (2018), we consider the EPU index as a potential predictor of the Bitcoin returns.

Furthermore, we run the Ordinary Least Squares (OLS) and the Quantile-on-quantile Regression (QQ) estimations to model the quantile of Bitcoin returns (including various frequencies) as a function of the quantile of the EPU index, which represents the each point of their distributions. ${ }^{3}$ We also analyze the lagged effects of the EPU on the Bitcoin returns.

\section{Empirical Results and Discussion}

We run the 60-day rolling window estimation technique with an initial sample period of 19 July 2010 to 15 September 2010 and 60-day rolling window estimation for the period from 16 September 2010 to 15 November 2017. In Figure 1, we present the Bayesian Information Criteria (BIC) scores of the multivariate autoregressive (MAR) and the multivariate instantaneous (MIN) dependence structures over the sample period. The result shows that the

\footnotetext{
${ }^{2}$ For more details about estimation and inference techniques, refer to Ahelegbey et al. (2016). Using the Markov Chain Monte Carlo (MCMC) process and the small-size networks methods, we estimate the LN component and the $\mathrm{CN}$ component. The MIN and the MAR structures respectively provide the posterior probabilities for the instantaneous and the lagged relationships between the logarithmic returns of Bitcoin and the EPU index.

${ }^{3}$ At this stage, we follow the QQ estimation methodology of Sim and Zhou (2015). For details, refer to Sim and Zhou (2015).
} 
MAR provides the best representation in accordance with the temporal dependence since the values of the MAR dependence are consistently smaller than the MIN dependence.

[Insert Figure 1around here]

In Figure 2, we further provide the percentage of the MAR links as obtained from the change in the EPU index to the Bitcoin returns for the MAR structures. Using the total (all) link, we observe that the period of highest interconnectedness is the year of 2012-13, and it is interesting to find the evidence of the structural breaks for the EPU index occurred on $1 / 26 / 2012$ and 3/03/2013, while the breaks for the total linkage happened on $1 / 27 / 2012$ and 9/09/2013. According to these findings, there is the lead-lag relationship for the breaks of the EPU index and the total linkage measures.

[Insert Figure 2 around here]

To examine the direction of this relationship, we provide the results of the OLS and the QQ estimations in Appendix Table I. According to the results of the OLS estimations, the effects of the EPU and the lagged EPU are negative and statistically significant at the $1 \%$ level. The evidence implies that an increase in EPU will lead to a decrease in the Bitcoin returns. However, the effect turns to be positive and significant at the lower and higher quantiles. Therefore, Bitcoin can be used for hedging against uncertainty during the times of bull-market (i.e. higher quantiles). At this stage, investors on cryptocurrencies can use these findings and they can incorporate the daily U.S. economic policy uncertainty into their investment decisions. Investors can predict the returns of Bitcoin via information from this uncertainty measure.

Our findings provide potential implications for portfolio diversification and hedging (risk management). According to our results, Bitcoin can be an alternative instrument for hedging against uncertainty. Our results are in line with Bouri et al. (2017), that is the relationship between uncertainty and Bitcoin returns are mainly negative, but Bitcoin can be 
used for hedging against uncertainty during the times of bull-market. Bitcoin can be considered for portfolio diversification during the times of bear-market.

It is also noteworthy to note that the future path of the EPU can serve as a measure of the vulnerability of Bitcoin market. Since the Bitcoin market is still in the growth process, the policymakers in the U.S. should realize that the uncertain environment in their economic policies could affect the Bitcoin returns. In the context of investors, they should watch not only the natural existing uncertainty of cryptocurrencies, but also the EPU to deal with the potential risks in the future.

\section{Conclusion}

In this paper, we examined the prediction power of the EPU on the daily Bitcoin returns for the period from July 18, 2010 to November 15, 2017. Using the BGSVAR model as well as the OLS and the QQ estimations, we found that the EPU has a predictive power on the Bitcoin returns. Mainly, the Bitcoin returns are negatively associated with the changes in the EPU. However, Bitcoin can be used a hedging tool against uncertainty in extreme times of uncertainty since we also found that the effect is positive and significant at the higher quantiles.

Future papers can use other uncertainty measures to analyze their effects on cryptocurrency markets. Indeed, we need to enhance our knowledge of the potential determinants of cryptocurrency markets.

\section{References}

Ahelegbey, D.F., Billio, M., Casarin, R. (2016). Bayesian graphical models for structural vector autoregressive processes. Journal of Applied Econometrics, 31 (2): 357-86. 
Baker, S.R., Bloom, N., Davis, S.J. (2016). Measuring economic policy uncertainty. Quarterly Journal of Economics, 131 (4): 1593-1636.

Bariviera, A.F. (2017). The inefficiency of Bitcoin revisited: A dynamic approach. Economics Letters, 161: 1-4.

Bouri, E., Gupta, R., Hosseini, S., Lau, C.K.M. (2018). Does global fear predict fear in BRICS stock markets? Evidence from a Bayesian Graphical Structural VAR model. Emerging Markets Review, doi:10.1016/j.ememar.2017.11.004

Bouri, E., Gupta, R., Tiwari, A.K., Roubaud, D. (2017). Does Bitcoin hedge global uncertainty? Evidence from wavelet-based quantile-in-quantile regressions. Finance Research Letters, 23: 87-95.

Cheah, E.T., Fry, J. (2015). Speculative bubbles in Bitcoin markets? An empirical investigation into the fundamental value of Bitcoin. Economics Letters, 130: 32-6.

Dyhrberg, A.H. (2016). Hedging capabilities of Bitcoin. Is it the virtual gold? Finance Research Letters, 16: 139-44.

Katsiampa, P. (2017). Volatility estimation for Bitcoin: A comparison of GARCH models. Economics Letters, 158: 3-6.

Nadarajah, S., Chu, J. (2017). On the inefficiency of Bitcoin. Economics Letters, 150: 6-9.

Nakamoto, S. (2008). Bitcoin: A Peer-To-Peer Electronic Cash System. Available at: https://bitcoin.org/bitcoin.pdf.

Sim, N., Zhou, A. (2015). Oil prices, US stock return, and the dependence between their quantiles. Journal of Banking and Finance, 55: 1-8.

Urquhart, A. (2016). The inefficiency of Bitcoin. Economics Letters, 148: 80-2.

Urquhart, A. (2017). Price clustering in Bitcoin. Economics Letters, 159: 145-8. 
Figure 1.

Bayesian Information Criteria of Contemporaneous and Temporal Dependence Structures

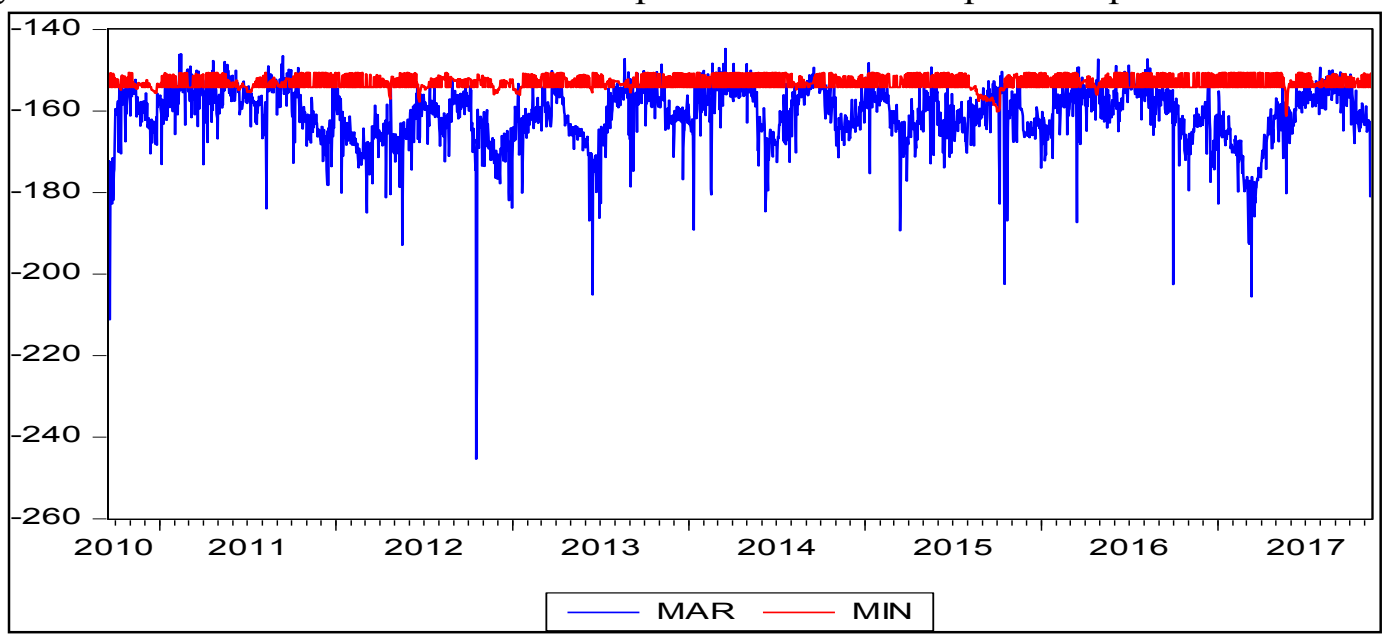

Figure 2.

Multivariate Autoregressive Model and the Lead-Lag Linkage

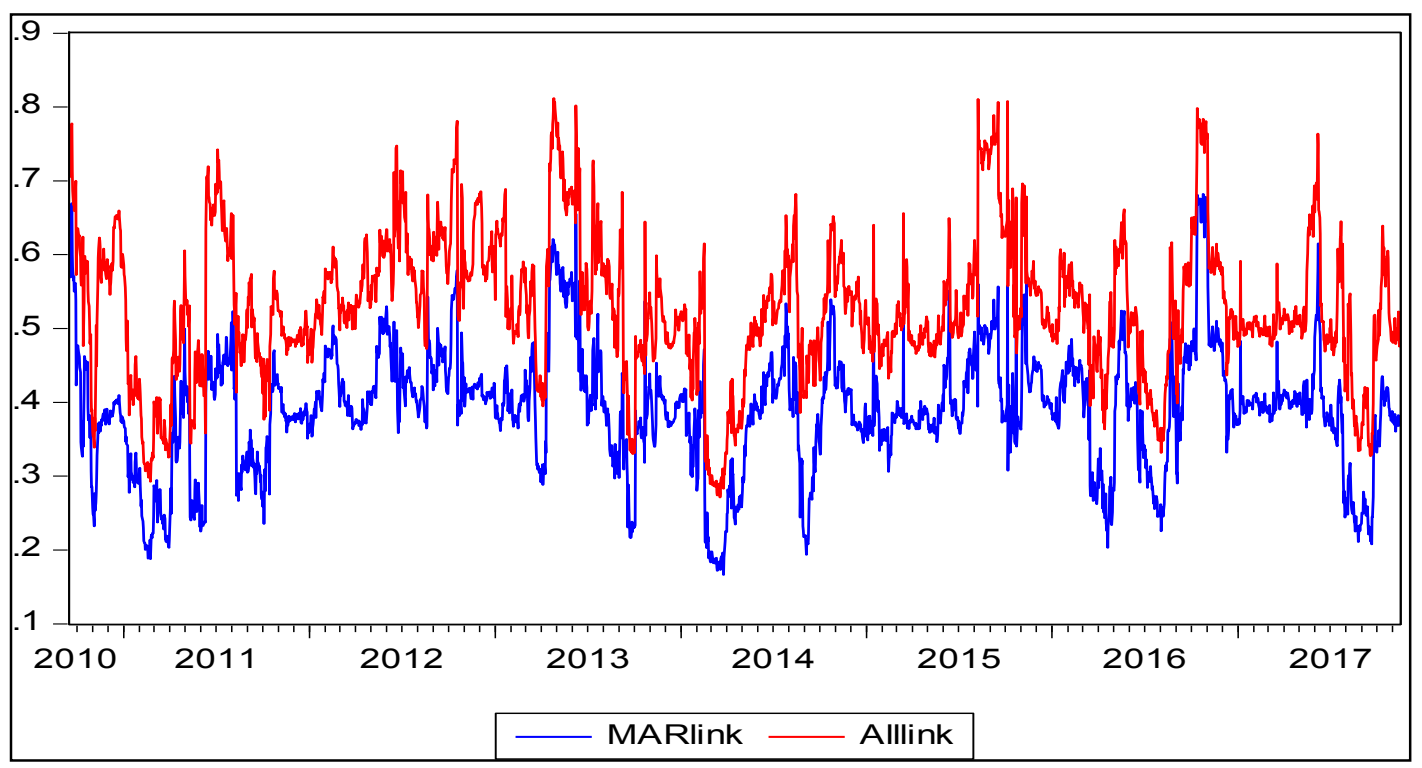


Appendix Table I.

Results of the OLS and the QQ Estimations

\begin{tabular}{|c|c|c|c|c|c|c|c|}
\hline Quantiles & EPU & $\operatorname{EPU}(-1)$ & $\operatorname{EPU}(-2)$ & $\operatorname{EPU}(-4)$ & $\operatorname{EPU}(-8)$ & $\operatorname{EPU}(-12)$ & $\operatorname{EPU}(-24)$ \\
\hline OLS & $-0.16 * * *$ & $-0.18 * * *$ & 0.23 & 0.07 & 0.03 & 0.18 & 0.48 \\
\hline 0.05 & 0.26 & 0.32 & 0.11 & 0.12 & 0.06 & 0.04 & 0.51 \\
\hline 0.10 & $0.23 *$ & 0.19 & 0.49 & 0.43 & 0.25 & 0.22 & 0.67 \\
\hline 0.15 & $0.19 * * *$ & 0.44 & 0.48 & 0.18 & 0.26 & 0.23 & $0.54 *$ \\
\hline 0.20 & $0.10 * *$ & 0.67 & 0.16 & 0.04 & 0.20 & 0.30 & 0.35 \\
\hline 0.25 & $0.55^{* *}$ & 0.09 & 0.06 & 0.01 & 0.19 & 0.12 & $0.29 *$ \\
\hline 0.30 & 0.21 & 0.13 & 0.03 & 0.02 & 0.07 & 0.11 & 0.15 \\
\hline 0.35 & -0.06 & -0.09 & -0.02 & -0.03 & $0.16^{*}$ & 0.07 & 0.14 \\
\hline 0.40 & $-0.16^{* *}$ & -0.05 & -0.01 & -0.08 & 0.11 & -0.03 & -0.19 \\
\hline 0.45 & $-0.17 * *$ & $-0.04 * *$ & $-0.02 * * *$ & $-0.04 * *$ & $-0.03^{*}$ & $-0.05 * *$ & -0.17 \\
\hline 0.50 & $-0.17 * *$ & -0.01 & -0.01 & -0.03 & -0.04 & -0.08 & 0.19 \\
\hline 0.55 & $-0.28 * *$ & -0.06 & -0.02 & -0.06 & -0.01 & -0.08 & 0.19 \\
\hline 0.60 & -0.17 & 0.09 & 0.03 & 0.02 & -0.03 & 0.11 & 0.18 \\
\hline 0.65 & $0.07 * * *$ & 0.16 & -0.09 & 0.12 & -0.04 & 0.08 & 0.23 \\
\hline 0.70 & 0.12 & 0.17 & -0.21 & 0.06 & -0.23 & 0.23 & $0.41 *$ \\
\hline 0.75 & $0.53 *$ & 0.03 & -0.16 & 0.11 & $-0.44 * *$ & 0.22 & 0.20 \\
\hline 0.80 & $0.12 * * *$ & 0.06 & -0.29 & 0.12 & $-0.38^{*}$ & 0.17 & 0.10 \\
\hline 0.85 & $0.19 * * *$ & 0.09 & 0.11 & 0.01 & 0.25 & 0.21 & 0.11 \\
\hline 0.90 & $0.27 * * *$ & 0.24 & 0.14 & 0.27 & 0.07 & 0.52 & 0.43 \\
\hline 0.95 & $0.23 *$ & 0.09 & $0.33^{*}$ & $0.81 *$ & 0.53 & $0.13^{*}$ & $0.15^{*}$ \\
\hline
\end{tabular}

